yield to a blister." And in 1854 ("On Inveterate Gonorrhœa and Gleet") he says, "My experience in these cases was, that not one in fifty would be cured by ordinary remedies; extraordinary remedies--those called for solely in inveterate caseswere blisters, \&c." Whilst in 1855 he adds, "I now, on the slightest sign of persistence (of gleet), proceed to use blisters."

Having thus demonstrated that the treatment, so far as I am concerned, is bereft of novelty, it will be advisable-before I point out the great advantage to be derived from a much more general use of blisters than is advocated by the writer just cited-that I should describe the class of subjects in whom this plan of treatment for gonorrhœa has been specially suc. cessful.

The men composing the two batteries of Royal Artillery at Halifax, Nova Scotia, are all young men of about five years' service, and their ages vary from twenty-two to twenty-seven years. As a rule, the gunners are very free from disease; and as the climate of this province, notwithstanding its wonderful changes, is highly salubrious, they suffer but little from diseases of an unfavourable type. Venereal complaints vary a good deal in type, and the number of cases is always greatly increased whenever the flag-ship is at the station. The sailors and marines, who appear to get almost unlimited "leave of absence," swarm in the countless brothels which exist in the neighbourhood of the barracks, and are prolific in spreading disease, as, however few may be the cases under treatment whilst the fleet is away, so soon as the ships return, cases of venereal disease are sure to spring up in abundance. So well is this known to the troops, that it is no uncommon expression to overhear from the men who watch the approach of the squadron from the West Indies, as they see the admiral's pennant in the flag-ship,_-_ Hullo! here comes old Veneral!"

In an admirable paper* in a recent number of the $E$ dinburgh Medical Journal, Dr. Marston has pointed out a complaint from which I apprehend the men under my charge suffer quite as frequently as the gunners at Malta. "Delirium e potu occurs in a man whose means prevent a regular steady soaking: but in one who drinks very hard whenever his pocket allows it. The subject of the disease goes in for a heavy night or so at a time: his money is exhausted; he does or does not go to prison; but at any rate he does not drink again for some period, for the best of all reasons-want of means. Here is the ordinary form of the disorder-an acute alcoholism; the drink being in the man. An emetic purgative, with quiet and repose for two or three days, sets him all right."

Now it is amongst such men, subject to periodic debauches in the way described above, that the cases of gonorrhoea occur. Practically, the advantage to the service and the assistance which is rendered towards furthering the ends of discipline by a rapid cure in such cases cannot be exaggerated. A young soldier is brought to hospital as a prisoner, having been found drunk for the fifth time in twelve calendar months, and suffering from "acute alcoholism." After three or four days, perhaps, he is tried by Court-Martial, and awarded twenty-eight days' solitary confinement with hard labour. On the sixth day from his quitting the hospital and the second of his punishment he finds he has "clap," and as a consequence is brought for readmission into hospital. Blisters are ordered to both thighs or to the penis, as the case may be, and in all probability the running will be found to have ceased entirely on the sixth day in the former, or the fourth day in the latter instance, after their application. The man is at once discharged from the hos pital and taken back to the cell, where he is able to undergo the remainder of his sentence.

It has been repeatedly alleged,-and I fear on very good grounds, though I am unable at this moment to quote the authority for the statement, - that "venereal cases constitute at least one-third of the whole admissions into military hospitals." The importance of a rapid cure can hardly be overestimated. Scarce anything in the daily routine of regimental duty is so annoying to the commanding officer or harassing to the surgeon, as the fact of a large batch of prisoners being found suffering from venereal complaints. Perhaps the day or so before a garrison field parade a good number of men go out on "pass" for the evening; probably the greater portion commit a debauch, and some of them may have had a slight running, which had not been detected. The next morning, prior to their being taken before the commanding officer, they are brought to the surgeon for medical inspection, the result being, that several of them have to be placed under treatment. The men then appear in hospital as regimental prisoners awaiting sentence. Or another circumstance-which is worse-may happen. The prisoners may appear perfectly well when inspected by the * On Delirium Tremens. medical officer, and after undergoing their sentence-extra drill as defaulters-for a day or two, may report themselves sick with gonorrhcea, \&c., for which it is necessary to take them into hospital, and thus they escape the remainder of the punishment a warded them. A very few years ago it was not uncommon for some "old" soldiers to be noted in every corps as men who always managed (if sentenced to defaulters' drill) to turn up in a short time with the complaint of an obstinate gleet that was sure to be troublesome on such occasions, or a swelled testicle which prevented them from going through with their punishment. Under the active medical supervision of the present day such cases, however, can rarely happen.

It will be obvious, $t$ think, from the circumstances which have been adduced, that if venereal affections cause a large proportion-"almost a moiety"-of the admissions into hospital, and thus make a serious inroad in the "duty states" of a regiment, nothing can be of greater moment, or deserving of more extended trial, than a plan of treatment which, whilst it is scarcely open to an objection, offers at once a speedy and effectual mode of cure, and returns the soldier's name to the list of "effectives for duty" in the shortest practicable time. The plan of treating cases of gonorrhoea by means of blisters was first brought to my notice in the summer of 1859 , in the wards of the Royal Artillery Hospital at Devonport, and $\mathbf{M r}$. Park, the accomplished surgeon in charge of the 3rd Brigade at that station, mentioned to me that he had adopted the plan, and with great success, for a considerable time.

On my taking charge of the batteries of Artillery in this country, I determined to give the plan as ample a trial as my practice permitted, and it is because of the conviction which $I$ entertain that the treatment by blisters is, far above all other, the best suited to soldiers -is the speediest in its result - the most effectual in its cure, and is that which is least open to tampering and deceit, that I now venture to submit some observations on the manner in which it is applied-on the cases to which it is adapted, and on the period within which a complete cure may be anticipated.

(To be continued.)

\section{REPORT OF A CASE}

or

\section{COM PRESSION OF THE BRAIN :}

\section{SYMPTOMS COMING ON NINE DAYS AFTER A FALL ON} THE OCCIPUT; FATAL RESULT; AUTOPSY.

By FRANCIS MASON, M.R.C.S.E., SURGEON TO THE ISLINGTON DISPENSARY, AND SURGEON TO THE ST. PANCRAS ROYAL GENERAL DISPEYYSARY.

Trre subject of this case is a well-developed, muscular, and healthy man, aged forty, superintendent of a cab-rank. Hestates that as he was going home from duty on Dec. 27 th, 1860, he slipped (the day being frosty) on a coal-cellar plate, and fell on the back of his head. He was stunned for a minute or two. Having been raised from the ground, he walked with but slight assistance to a neighbouring shop, where he was supplied with some brandy-and-water. In a short time he recovered sufficiently to walk to his home (a distance of nearly a mile) without any aid, and says that on his arrival he felt as well as usual. He informed his wife of the accident, but made no complaint whatever; in fact, he was so little affected that, on the same evening, he much enjoyed a game at "snow-balls," in which he took a most active part. He went to his duty regularly until Jan. 5th, 1861 (the ninth day after the accident), when he felt severe pain in the region of the occiput. He therefore walked, on Jan. 7th, to see Mr. Painter, the divisional surgeon, who prescribed for him. From domestic affliction Mr. Painter became unable to attend him, and I was therefore requested by the friends to see the patient.

Jan. 10th. - I found the patient lying in bed in a rather drowsy condition, and complaining of intense pain at the occiput. He is quite sensible, answering questions rationally and distinctly. He has not been sick, but feels slightly so. There is palsy of the muscles of the left :ide of the face; sensation is, however, nearly perfect. He cannot whistle, and can only partially close the left eyelid. There is also palsy of the external rectus of the left eye. The pupils are not permanently 
dilated, nor are they contracted ; each acts well on the application of light. Vision in the left eye not quite so good as that in the right. There is some little difficulty in swallowing. The tongue is protruded with ease, and points towards the palsied side of the face. No palsy of the arms or legs. Is rather deaf with the left ear. There is no stertorous breathing; skin hot and perspiring; pulse 60 , full ; respiration 30 , occasionally of a sighing character; appetite unimpaired; complains of being rather thirsty; passes urine, and retains fæces, naturally; bowels moved yesterday. There is no external mark of injury, excepting a slight abrasion of the skin at the occiput, at the spot which came in contact with the ground when he fell. There is no apparent depression of bone, and manipulation gives no pain. He was ordered to be kept as quiet as possible, and to have an evaporating lotion for the head.

12th. - To-day he seems more composed. Pulse 60 ; respiration 32 ; palsy of face and other symptoms about the same. Takes beef-tea and milk as nourishment. Bowels have not been moved since the 9 th. Ordered ten grains of calomel, to be taken immediately.

14th. - He says he does not feel quite so well; pain in the head still continues. Sleeps badly at night-only about ten minutes at a time. Bowels have been freely moved. Pulse 62 ; respiration 30 ; tongue thickly furred.

17th. - His wife says that last night he was delirious for about an hour. Pulse 70 ; respiration 40 . He does not com. plain so much of the pain in his head. Appetite still remains good, but he is decidedly weaker.

18th. - To-day there is a decided improvement; he has had a quiet night; countenance not so expressive of anxiety. Bowels have been moved naturally without medicine. Pulse 4 ; respiration $32 . \quad$ He is quite conscious; does not pass urine involuntarily, and can retain the fæces.

Feb. 22nd.-Has been progressing favourably up to to-day, when the breathing became suddenly stertorous for about two hours. He is much weaker, and there is evidently a want of power in the right arm; still he is quite conscious of all that is going on around him. Pulse 100 ; respiration 49 ; appetite not so good.

24th. - Remains in the same condition. No return of stertorous breathing. There is difficulty in swallowing; he does not take food when offered to him. Pulse 120 ; respiration 48 . 25th. - He gradually sank, and died to.day.

A utopsy fifty-seven hours after death. - Body well nourished and healthy. No other mark of external injury excepting the abrasion and redness at the most prominent part of the occipnt, at the spot alluded to in the above history. On removing the scalp there was no ecchymosis found underneath, the skull presenting a healthy surface without any sign of fracture. On removing the skull-cap, the dura mater was seen to be perfectly normal. The surface of the brain was slightly congested; no extravasation of blood. On removing the brain, a clot of blood the size of two small walnuts was seen, situate under the left side of the pons Varolii. No fracture at the base of the skull could be discovered. Brain substance and arteries of the brain healthy. Other organs not examined.

Woburn-square, 1861

\section{Alintor}

OF THE PRACTICE OF

\section{MEDICINE'AND SURGERY IN THE}

\section{HOSPITALS OF LONDON.}

Nulla est alia pro certo noscendi via, nisi quam plurimas et morborum et dissectionum historias, tam aliorum proprias, collectas habere et inter se com parare.-Mongagn. De Sed, et Caus. Worb., lib. 14. Proœmium.

\section{WESTMINSTER HOSPITAL.}

ANEURISM OF THE CAROTID ARTERY; LIGATURE OF THE LOWER PART OF THE VESSEL; SUCCESSFUL RESULT.

\section{(Under the care of Mr. Hoz'T.)}

IT is now well known that the most common cause of death after the carotid artery has been tied for aneurism, wounds, erectile tumours, \&c., is cerebral disease, induced by a dimi nished supply of blood to the brain, or by increased pressure, or, again, by actual inflammation. Persons who have undergone ligature of the carotid may recover from the immediate effects of such a proceeding, and leave the hospital for their homes comparatively well. Nevertheless, cerebral disease may afterwards appear, and proceed to a fatal result, the disease remaining unknown to the surgeon who has so anxiously watched his patient from day to day whilst under his care. Now in the following case the carotid was tied for an aneurism, and although there were some drawbacks subsequently, such as suppuration and hæmorrhage, yet the patient left the hospital nearly twelve weeks afterwards, free from any cerebral symptoms; for the present, therefore, recovery may be said to have resulted. We trust, however, that some months hence the man's general condition may be not less favourable.

In a previous "Mirror" we placed upon record an instance, under the care of Mr. Le Gros Clark at St. Thomas's Hospital, (The LANCET, vol. i., 1860, pp. 141, 244,) in which the external carotid was ligatured on Jan. $23 \mathrm{rd}, 1860$, for a wound, the patient being a bricklayer aged twenty-seven. He went on well, the ligature came away on the sixteenth day, and he left the hospital in good health and resumed his work. Nearly twelve months after the operation he was seen by Mr. Clark, and was found to be still in good health. It is but fair to conclude, therefore, that a permanent recovery has taken place, and that there is now no danger of secondary cerebral disturbance.

For the notes of the following case we are indebted to $\mathrm{Mr}$. W. Slater, late house-surgeon to the hospital:-

George $\mathrm{U}-$, aged thirty, was admitted Nov. 13th, 1860. He states that in September last, when lifting a heavy stone, he sprained his neck. About a fortnight after this, he noticed a soreness in the course of the right common carotid artery, and at this time he began to lose flesh, and altogether felt very ill. A week after, he noticed a small, hard swelling, of the size of a marble, over the common carotid artery, on the right side, and about two inches above the sterno-clavicular articulation. Ten days afterwards he came to the hospital, and at this time there was a hard lump, a Jittle larger than a walnut, situated in the course of the carotid artery, extending from about one inch above the sterno-clavicular articulation to about three inches below the ear. There was a distinct pulsation, but no bruit, in the tumour; there was no fluctuation, and it could not be emptied, but it was very painful on pressure. About a week after he came to the hospital again, and was seen by Mr. Holt. The tumour had evidently increased rapidly; but taking into consideration that the man was of a scrofulous constitution, and had had several enlarged glands in the neck before, Mr. Holt considered this swelling to be an eularged gland situated above the artery, which was ordered to be brushed over with tincture of iodine every other day. On his admission on Nov. 13th, the tumour had spread very much downwards, and was much softer. There was a distinct blowing sound to be heard, and the tumour could be emptied by applying pressure, either directly to it, or on the artery below it. He complained of pain in the back of the head, and, at times, in the shoulder and down the right arm. There was no numbness or want of sensation in the arm. Ice was ordered to be kept constantly applied to the tumour, and a dose of compound powder of jalap was administered.

Nov. 20th. - The tumour has increased in size, and Mr. Holt therefore determined to operate at once. The man having been put fully under the infiuence of chloroform, an incision about an inch and a half long was made along the border of the sterno-mastoid muscle down to the sterno-clavicular articulation, another incision being carried along the upper border of the clavicle, and the flap turned back. Mr. Holt then carefully dissected down upon the artery, which he found without the least difficulty, and a ligature was put upon it about an inch from the bifurcation of the innominata. The patient was immediately placed in bed, and water dressing was applied to the part. He had a quiet night.

21 st.-Ten A.M.: Rather restless; pulse 100; tongue dry and brown; complains of a good deal of pain in the wound, but has none in the head. Ordered broth and six ounces of wine.-Six P.M.: Not so restless; pulse 100; tongue the same; not so much pain in the wound.

$22 \mathrm{nd}$. - Slept pretty well; woke at intervals; had a slight headache over the right frontal and parietal region this morning, but it did not last long; bowels not open since the operation; pulse 105; tongue still rather brown and coated; respirations 28 , calm and natural; a slight moisture apparent over the right side of the face; aspect altogether improved was reading at times, and taking notes; says he feels occasionally a slight shooting pain across the right mammary region; wound looks clean and healthy; very sl ght discharge; 